\title{
The selective detection of dopamine at a polypyrrole film doped with sulfonated $\beta$-cyclodextrins
}

\author{
Claire C. Harley*, A. Denise Rooney, Carmel B. Breslin \\ Department of Chemistry, National University of Ireland Maynooth, Maynooth, Co. Kildare, Ireland
}

\section{A R T I C L E I N F O}

\section{Article history:}

Received 8 June 2010

Received in revised form 27 August 2010

Accepted 7 September 2010

Available online 17 September 2010

\section{Keywords:}

Dopamine sensor

Polypyrrole

$\beta$-Cyclodextrin

Ascorbic acid

Selective detection

\begin{abstract}
A B S T R A C T
A highly selective dopamine sensor was fabricated by doping polypyrrole with a sulfonated $\beta$ cyclodextrin. This composite material enabled the selective sensing of dopamine in the presence of a large excess of ascorbic acid and prevented the regeneration of dopamine through the homogeneous catalytic reaction of the ascorbate anion with the dopamine-o-quinone. A single redox wave, corresponding to the oxidation of dopamine, was observed in dopamine/ascorbate mixtures, giving a truly selective dopamine sensor. The limit of detection was measured as $3.2 \times 10^{-6} \mathrm{M}$ for dopamine.
\end{abstract}

(c) 2010 Elsevier B.V. All rights reserved.

\section{Introduction}

Dopamine is one of the most important catecholamine neurotransmitters in the mammalian central nervous system. Abnormalities in dopamine concentrations have been linked with several neurological disorders such as the debilitating ailment Parkinson's disease and the mental disorder schizophrenia [1,2]. Dopamine is also believed to play a central role in Huntington's disease, a fatal genetic neurodegenerative movement disorder and has also been associated with drug addiction and attention disorders [3-5].

Monitoring the concentration of dopamine is particularly challenging using electrochemical methods because dopamine coexists with many interfering compounds in biological samples. These interfering compounds are usually present at concentrations much higher than dopamine and, moreover, they are oxidised at similar potentials to dopamine at most solid electrodes. This is particularly true of ascorbic acid, the main interfering compound in the determination of dopamine. The concentration of the ascorbate anion is typically $10^{-3} \mathrm{M}$, while the concentrations of dopamine are considerably lower, in the range of $10^{-8}$ to $10^{-6} \mathrm{M}$. Ascorbic acid is easily oxidised having a range of $E_{1 / 2}$ values between -100 and $400 \mathrm{mV}$ vs. SCE on most solid electrodes. This lies in the same potential region as dopamine, which has a range of $E_{1 / 2}$ values between 100 and $250 \mathrm{mV}$ vs. SCE for various electrode substrates [6]. Furthermore, ascorbic acid reacts with the oxidised dopamine

\footnotetext{
* Corresponding author. Tel.: +3531 708 3770; fax: +3531 1083815

E-mail address: claire.c.harley@nuim.ie (C.C. Harley).
}

product (dopamine-o-quinone) which is generated through the electrochemical oxidation of dopamine. This reaction leads to the regeneration of dopamine making it available for further electrochemical oxidation, complicating the analysis $[7,8]$.

A number of modified electrodes have been used in an attempt to resolve these problems. The most popular strategies include polymer, self-assembled monolayer, metal nanoparticle, carbon nanotube and surfactant modified electrodes [9-13]. In particular, there has been much interest in the development of sensors based on electrodes modified with polymeric films. Electropolymerised films of pyrrole, aniline, 3-methylthiophene, acridine red, sulfosalicylic acid, 3,5-dihydroxy benzoic acid and acid chrome $\mathrm{K}$ have all been reported [14-18]. Overoxidised polymer modified electrodes have also been employed to sense dopamine and ascorbic acid [19]. However, the most common approach is to use Nafion ${ }^{\circledR}$, a perfluorinated polymer. Nafion ${ }^{\circledR}$ has terminal sulfonate groups that can repel the negatively charged ascorbate anion from the electrode surface, enabling the discrimination of the ascorbate and dopamine oxidation waves [20].

Cyclodextrins are naturally occurring macrocyclic oligosaccharides built from $\alpha-1,4$-linked D-glucopyranose units. Cyclodextrins are well-known to bind with suitable guest molecules in aqueous solutions to form inclusion complexes [21]. They also exhibit excellent biocompatibility and as a result have been incorporated into various dopamine sensors. For example, Izaoumen et al. [22] and Bouchta et al. [23] have used polymer films modified with neutral cyclodextrins and doped with perchlorate anions for the sensing of dopamine, while Alarcon-Angeles et al. [24] have modified multiwall carbon nanotubes with $\beta$-cyclodextrins for the sensing 
of dopamine. The electrochemical synthesis of polypyrrole doped with sulfonated $\beta$-cyclodextrins has been reported by Temsamani et al. [25], Bidan et al. [26] and Reece et al. [27]. However, there are no reports, to the best of our knowledge, on using these materials in the selective sensing of dopamine. The modified sensor used here differs from the majority of all other publications on cyclodextrin modified dopamine sensors, as the anionic cyclodextrin is introduced into the polymer matrix as an immobile dopant. Furthermore, it is the sole dopant, as no other anions are used in the electropolymerisation step.

In this paper, we show that polypyrrole films doped with sulfonated $\beta$-cyclodextrins are readily formed and that these materials have excellent selectivity in the determination of dopamine concentrations, facilitating the oxidation of dopamine, but inhibiting the oxidation of ascorbate. In addition, there is no evidence of the regeneration of dopamine through the ascorbate/dopamine-oquinone reaction. Also, the exceptional biocompatibility properties of the materials used make the cyclodextrin-doped polypyrrole sensor considerably more suitable for in vivo detection compared to some of the more complex electrodes already considered in the sensing of dopamine.

\section{Experimental}

\subsection{Materials}

Dopamine, ascorbic acid, pyrrole, citric acid, disodium hydrogen phosphate and sulfonated $\beta$-cyclodextrin were obtained from Sigma-Aldrich or its subsidiary company, Fluka. All chemicals were used as supplied except for the pyrrole monomer which was distilled before use and stored at $-4{ }^{\circ} \mathrm{C}$. All solutions were prepared freshly before each experiment and were deoxygenated with nitrogen. Platinum rod (99.95\%, $4 \mathrm{~mm}$ in diameter) and glassy carbon ( $4 \mathrm{~mm}$ in diameter) were supplied by Goodfellow or Alfa Aesar. A $250 \mathrm{~mL}$ citrate phosphate buffer solution ( $\mathrm{pH}$ 6.0) was prepared by mixing $150 \mathrm{~mL}$ of $0.2 \mathrm{M}$ disodium hydrogen phosphate and $100 \mathrm{~mL}$ of $0.1 \mathrm{M}$ citric acid.

\subsection{Apparatus}

The performance of the sensor was evaluated using both cyclic voltammetry measurements and constant potential amperometry. All data were recorded using a Solartron $1285 \mathrm{~A}$ potentiostat at room temperature in a $0.10 \mathrm{M} \mathrm{Na}_{2} \mathrm{SO}_{4}$ supporting electrolyte, $\mathrm{pH}$ 6.0. The constant potential amperometry was performed by rotating the electrode at $2000 \mathrm{rpm}$ using a rotating disc electrode assembly, EG\&G Model 363. A platinum rotating disc electrode was used as the working electrode. In each case, the modified electrodes were first cycled in the background electrolyte, between $-0.10 \mathrm{~V}$ vs. SCE and $0.90 \mathrm{~V}$ vs. SCE for 10 cycles to ensure the release of any pyrrole or oligomers from the surface.

A standard three-electrode electrochemical cell configuration was employed for all electrochemical experiments. A platinum or glassy carbon rod electrode was used as the working electrode. These were embedded in epoxy resin in a Teflon holder with electrical contact being achieved by means of a wire threaded through the holder to the rod substrate. A platinum wire was used as an auxiliary electrode and a saturated calomel electrode (SCE) was used as the reference electrode. Tencor analysis was carried out on a Tencor Veeco Dektac 6M Stylus Profilometer in the Tyndall National Institute, University College Cork.

\subsection{Fabrication of polymers}

Prior to each experiment, the platinum electrode was polished to a mirror finish, using successively smaller sizes of diamond paste,
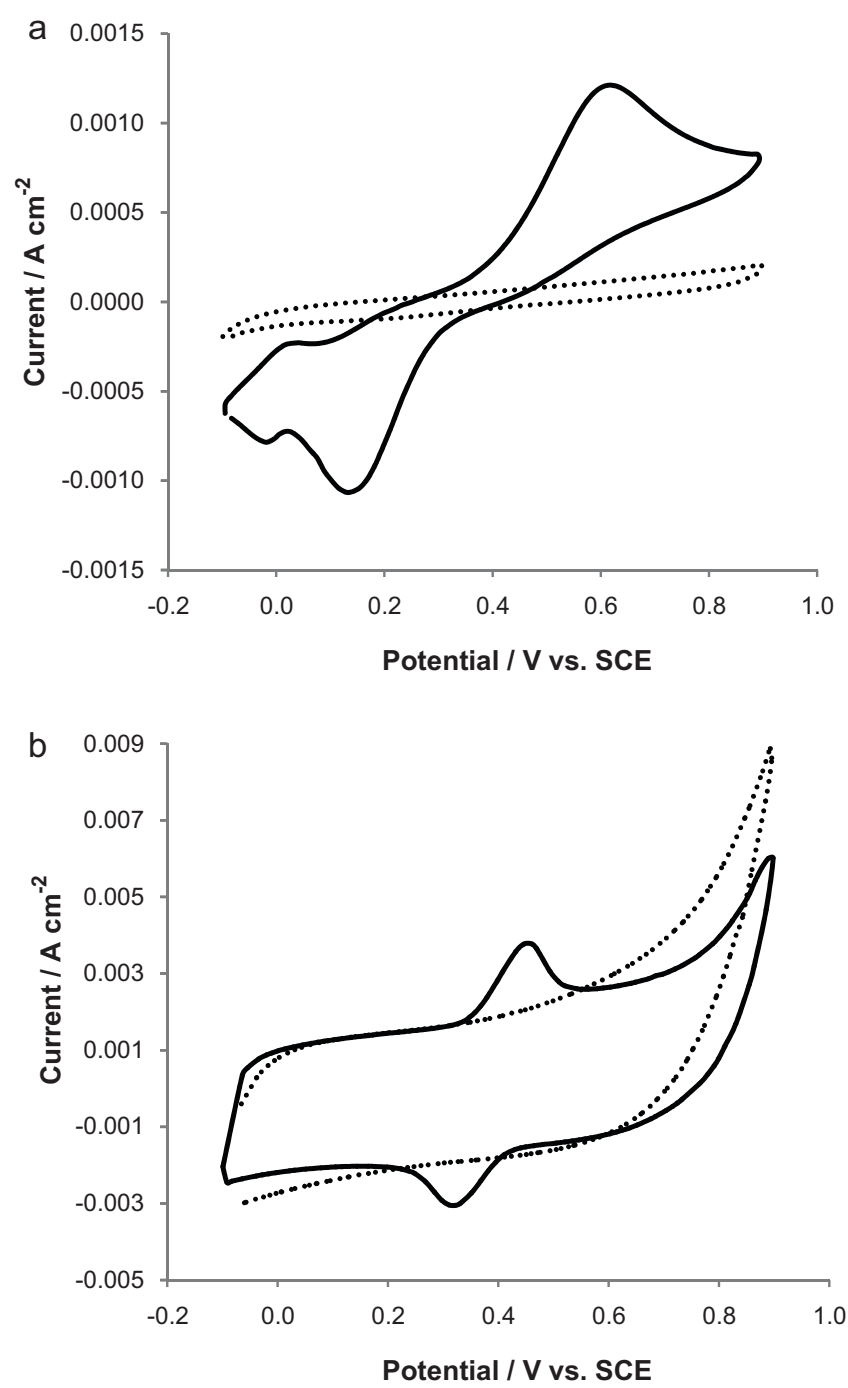

Fig. 1. Cyclic voltammograms of (a) bare platinum electrode and (b) a polypyrrole sulfonated $\beta$-cyclodextrin modified electrode in (..) a $0.10 \mathrm{M} \mathrm{Na}_{2} \mathrm{SO}_{4}$ solution and in (-) a $1.0 \times 10^{-3} \mathrm{M}$ dopamine/ $0.10 \mathrm{M} \mathrm{Na}_{2} \mathrm{SO}_{4}$ solution. Scan rate $=100 \mathrm{mV} \mathrm{s}^{-1}$.

down to a $1 \mu \mathrm{m}$ sized diamond paste, rinsed with distilled water and finally cleaned in an ultrasonic bath. The cyclodextrin doped polypyrrole films were prepared at the platinum electrode from a $0.20 \mathrm{M}$ pyrrole and $0.01 \mathrm{M}$ sulfonated $\beta$-cyclodextrin solution ${ }^{1}$ at a constant potential of $0.80 \mathrm{~V}$ vs. SCE until a charge of $0.24 \mathrm{C} \mathrm{cm}^{-2}$ was passed (approximately $35 \mathrm{~s}$ ). The polypyrrole sulfonated $\beta$ cyclodextrin modified electrode was finally washed with distilled water and dried.

\section{Results and discussion}

\subsection{Oxidation of dopamine at the polypyrrole sulfonated $\beta$-cyclodextrin film}

The dopamine response at the bare platinum electrode and at the polypyrrole sulfonated $\beta$-cyclodextrin film was examined using cyclic voltammetry, Fig. 1(a) and (b), respectively. The electrodes were cycled in a $1.0 \times 10^{-3} \mathrm{M}$ dopamine solution dissolved in a

\footnotetext{
1 Commercially available sulfonated $\beta$-cyclodextrin has approximately 7-11 sulfonated groups per cyclodextrin. A mean value of 9 sulfonated groups was assumed when calculating the molecular weight.
} 
$0.10 \mathrm{M} \mathrm{Na}_{2} \mathrm{SO}_{4}$ supporting electrolyte, between $-0.10 \mathrm{~V}$ and $0.90 \mathrm{~V}$ vs. SCE at a scan rate of $100 \mathrm{mV} \mathrm{s}^{-1}$. It can be seen in Fig. 1(a) that the oxidation of dopamine at the bare platinum electrode exhibits two pairs of redox peaks. The pair of redox peaks observed at the higher potentials corresponds to the oxidation of dopamine to dopamine-o-quinone, whereas the redox couple observed at the lower potentials relates to the oxidation of leucodopamine to dopaminochrome. These redox peaks are consistent with the electrochemical oxidation of dopamine at unmodified substrates [28].

The electrochemistry of dopamine at the polypyrrole sulfonated $\beta$-cyclodextrin film is very different (Fig. 1(b)). Only one pair of redox peaks, corresponding to the oxidation of dopamine $(0.46 \mathrm{~V}$ vs. SCE) and the reduction of the dopamine-o-quinone $(0.27 \mathrm{~V}$ vs. SCE), is observed and the peaks currents are considerably higher. This marked increase in the peak current can be attributed to the polymer and not the metal surface. Indeed, this is further supported by the fact that the oxidation potential of dopamine at the polymer-modified electrode is some $150 \mathrm{mV}$ lower than that observed at the bare platinum electrode. In addition, the presence of this polymer on the platinum electrode has decreased the potential difference between the oxidation and reduction peaks of dopamine, making the reaction more reversible than that observed at a bare platinum electrode. The peak potential separation $\left(\Delta E_{\mathrm{p}}\right)$ is approximately $190 \mathrm{mV}$ at the polymer modified electrode, compared to $480 \mathrm{mV}$ at the bare platinum electrode, indicating a significant increase in the reversibility of the system. This increase may be attributable to improved kinetics, however, the rate constant, $k$, was found to be $3.9 \times 10^{2} \mathrm{M}^{-1} \mathrm{~s}^{-1}$ at the polymer modified electrode. This was determined using rotating disc voltammetry and the Koutecky-Levich equation, $1 / i_{L}=1 / n F A C_{o} k \Gamma+1 / 0.62 n F A D^{2 / 3} v^{-1 / 6} C_{o} \omega^{1 / 2}$, where, $i_{L}$ is the measured limiting current, $n$ is the number of electrons transferred, $F$ is the Faraday constant, $A$ is the electrode area, $C_{o}$ is the dopamine concentration, $k$ is the rate constant, $\Gamma$ is the surface coverage, $D$ is the diffusion coefficient, $v$ is the kinematic viscosity and $\omega$ is the rotation speed. If a linear Koutecky-Levich relationship exists between the inverse of the limiting current and the inverse of the square root of the rotation speed then $k$ can be determined from the intercept of this line. This value for $k$ is reasonably high, indicating a fairly fast electrocatalytic process. However, higher rate constants have been reported in the literature $[29,30]$. Therefore, the obvious increase in the reversibility may not be solely due to the polymer film having a catalytic effect on the oxidation of dopamine.

Another aspect that must be taken into consideration is the porous nature of the polymer film. The thickness of the polypyrrole sulfonated $\beta$-cyclodextrin film was determined as $505 \pm 50 \mathrm{~nm}$ using a Tencor profilometer. The thickness of the films was also theoretically calculated as $600 \mathrm{~nm}$ from the total charge passed using a relationship derived by Diaz et al. [31] that assumes that $1 \mathrm{Ccm}^{-2}$ is equivalent to $2.5 \mu \mathrm{m}$ of polymer growth. This is slightly higher than the experimental analysis however, it is important to highlight that the relationship quoted by Diaz et al. [31] was for a simple chloride dopant, which has been shown to form thicker films than polypyrrole films doped with tosylate and polystyrene sulfonate when the same amount of charge has been passed [32]. The values obtained from both the experimental and theoretical analyses indicate that the polypyrrole sulfonated $\beta$-cyclodextrin films are porous and may exhibit thin film diffusion. Henstridge et al. [33] have shown that a reduction in the overpotential of a voltammetric signal at a porous film is due to planar diffusion and thin film diffusion rather than a faster rate of electron transfer. Therefore, the more reversible electrochemistry of dopamine at the polypyrrole sulfonated $\beta$-cyclodextrin film may be also connected with this phenomena.

Another characteristic of the voltammograms recorded by the polymer film is that the dopamine oxidation peak is more symmet-
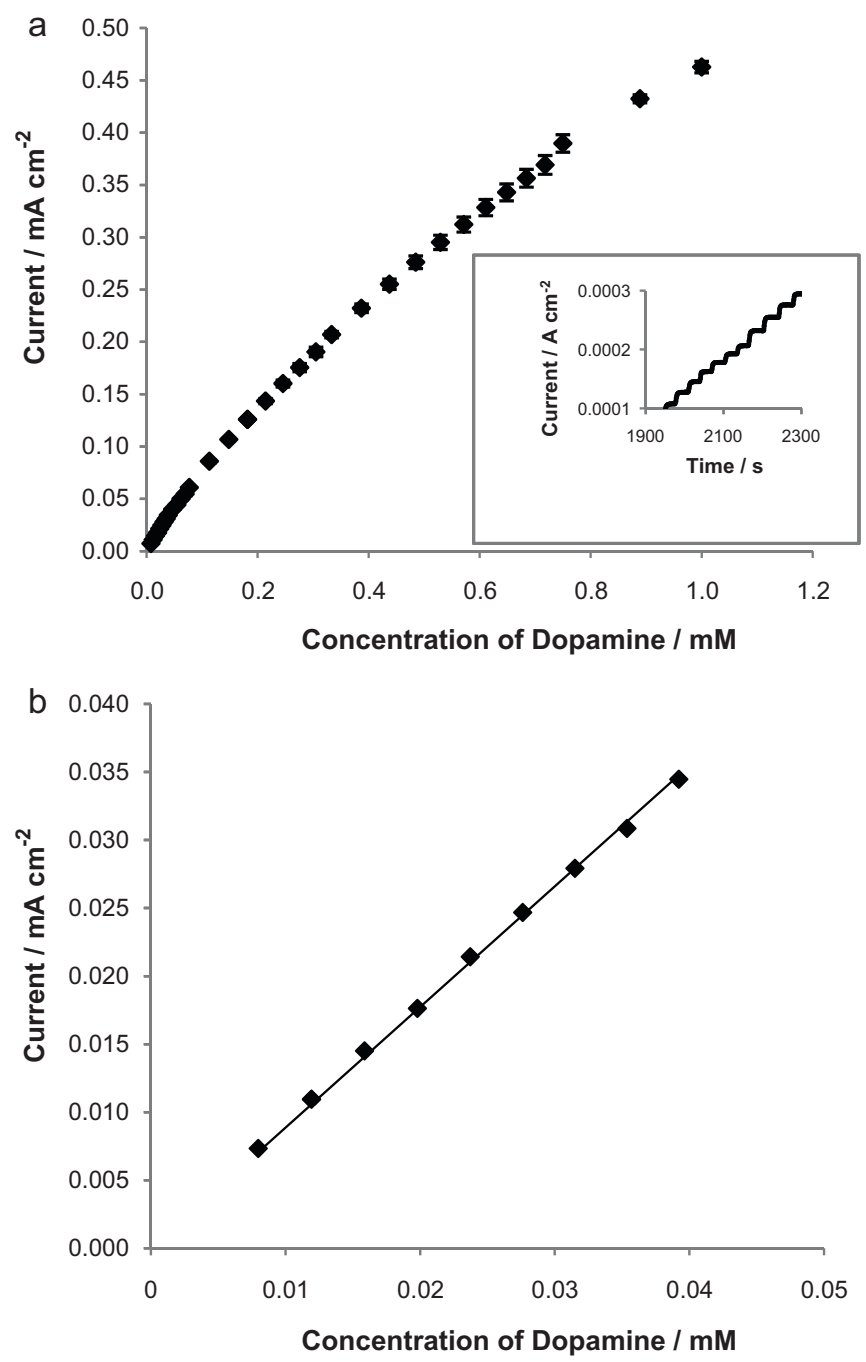

Fig. 2. (a) Steady-state currents from constant potential amperometry, recorded at a rotating disc electrode at $2000 \mathrm{rpm}$ at $0.65 \mathrm{~V}$ vs. SCE, plotted as a function of the dopamine concentrations $(n=4)$. Inset shows the constant potential amperometry with current plotted as a function of time and as a function of successive additions of dopamine aliquots ranging from $50 \mu \mathrm{L}$ to $5 \mathrm{~mL}$. (b) The linear response of dopamine at low concentrations.

ric in comparison to the bare electrode. This may be connected to the capacitance of the polymer film. As evident in Fig. 1(b), the background current in the cyclic voltammograms is large, indicating a high charging capacitance. Indeed, the capacitance of the polypyrrole sulfonated $\beta$-cyclodextrin film was found to be $1.2 \times 10^{-3} \mathrm{~F} \mathrm{~cm}^{-2}$ which is significantly higher than the capacitance associated with the bare platinum electrode. This higher capacitance may be responsible for the more symmetric shape of the dopamine oxidation wave. Indeed, it has been shown that the cyclic voltammograms of dopamine can become more symmetric in shape as the capacitance increases [34].

\subsection{Sensitivity of the polypyrrole sulfonated $\beta$-cyclodextrin film}

In order to obtain information on the sensitivity of the sensor, constant potential amperometry data were measured. A typical plot is presented in the inset of Fig. 2(a), showing the amperometric response of the cyclodextrin-doped polypyrrole film to successive additions of dopamine. The solution was agitated by rotating the electrode at $2000 \mathrm{rpm}$, while a constant potential of $0.65 \mathrm{~V}$ vs. SCE was applied. The response time (time for the signal to increase from 
$10 \%$ to $80 \%$ ) was less than $3.3 \mathrm{~s}$, which indicates a reasonably quick response of the modified electrode to dopamine. This compares very well with the typical response times of dopamine at other modified electrodes [35].

The relationship between the measured current and the concentration of dopamine is shown in Fig. 2(a). A curve is obtained over a wide concentration range, while a clear linear region is observed at lower concentrations, as shown in Fig. 2(b). The regression equation was $I_{\mathrm{pa}}=0.886 c_{\mathrm{DA}}$, with a correlation coefficient of 0.999 . This gives a current to concentration ratio of $0.886 \mu \mathrm{A}_{\mu} \mathrm{M}^{-1}$. This sensitivity is reasonable given the fact that the sensitivities of the majority of polymer modified dopamine sensors are similar, if not, lower than this. For example, Gopalan et al. [36] obtained a sensitivity of $0.22 \mu \mathrm{A} \mu \mathrm{M}^{-1}$ in the presence of ascorbic acid using a poly(4-aminothiophenol) modified electrode embedded with gold nanoparticles while Balamurugan and Chen [37] acquired a sensitivity of $1.0 \mu \mathrm{A} \mu \mathrm{M}^{-1}$ for dopamine using an poly(3,4-ethylenedioxythiophene-co-(5amino-2-naphthalenesulfonic acid)) modified electrode.

Using the linear calibration curve, the limit of detection was found to be $3.2 \times 10^{-6} \mathrm{M}$ dopamine. This was obtained using the expression $C_{\mathrm{m}}=3 S_{\mathrm{b}} / \mathrm{m}$, where $C_{\mathrm{m}}$ is the detection limit, $S_{\mathrm{b}}$ is the standard deviation of the blank response and $m$ is the slope of the linear calibration curve. Although this concentration is not sufficiently low for a viable in vivo dopamine sensor, it may be possible to reach lower detection limits by using pulsed techniques, such as differential pulse voltammetry, or by miniaturising the electrode. Interestingly, a limit of detection of $4.0 \times 10^{-5} \mathrm{M}$ dopamine, obtained by Ferreira et al. [38], was sufficient to detect dopamine in a pharmaceutical product. Therefore, the polypyrrole sulfonated $\beta$-cyclodextrin modified electrode may have potential in this area.

\subsection{Effect of ascorbic acid on the sensing of dopamine}

In Fig. 3(a), the cyclic voltammograms of the cyclodextrin doped polypyrrole films cycled in $1.0 \times 10^{-3} \mathrm{M}$ dopamine and in $1.0 \times 10^{-3} \mathrm{M}$ ascorbate are compared. In both cases, the potential is cycled in the potential range where dopamine and ascorbate are likely to oxidise. No oxidation wave is observed for the ascorbate system at the polypyrrole sulfonated $\beta$-cyclodextrin film. When ascorbic acid and dopamine are simultaneously mixed in the same solution, only the dopamine peak is detected at the polypyrrole sulfonated $\beta$-cyclodextrin electrode, giving very good selectivity, Fig. 3(a).

The influence of ascorbate on the dopamine signal is summarised in Fig. 3(b) and (c), where the magnitude of the oxidation peak currents and potentials obtained with pure dopamine, are compared to the values measured when $1.0 \times 10^{-3} \mathrm{M}$ ascorbate is present. The concentration ratio of ascorbic acid to dopamine in the combined solution was varied from $1.0\left(1.0 \times 10^{-3} \mathrm{M}\right.$ ascorbic acid and $1.0 \times 10^{-3} \mathrm{M}$ dopamine $)$ to $16.7\left(1.0 \times 10^{-3} \mathrm{M}\right.$ ascorbic acid and $6.0 \times 10^{-5} \mathrm{M}$ dopamine). The values reported are averaged over at least three determinations (the errors in the measurements are less than $1.5 \%$ ). It can be seen that the dopamine signal is not affected by the presence of ascorbic acid. Also, regardless of the concentration of dopamine, there is no evidence of any increase in the dopamine oxidation current as a result of the solution reaction between dopamine-o-quinone and ascorbic acid (Scheme 1).

In fact, no interference was observed when the concentration of ascorbic acid was increased to $1.0 \times 10^{-2} \mathrm{M}$. At this high concentration the oxidation peak from ascorbic acid should be sufficient to overcome the background current. The mean $I_{\mathrm{p}}$ and $E_{\mathrm{p}}$ values for $1.0 \times 10^{-3} \mathrm{M}$ dopamine at the polymer film were $3.65 \times 10^{-3} \mathrm{~A} \mathrm{~cm}^{-2}$ and $0.459 \mathrm{~V}$ vs. SCE, respectively $(n=3)$. Surprisingly, mean $I_{\mathrm{p}}$ and $E_{\mathrm{p}}$ values of $3.64 \times 10^{-3} \mathrm{~A} \mathrm{~cm}^{-2}$ and $0.459 \mathrm{~V}$ vs. SCE were obtained in the presence of $1.0 \times 10^{-2} \mathrm{M}$ ascorbate
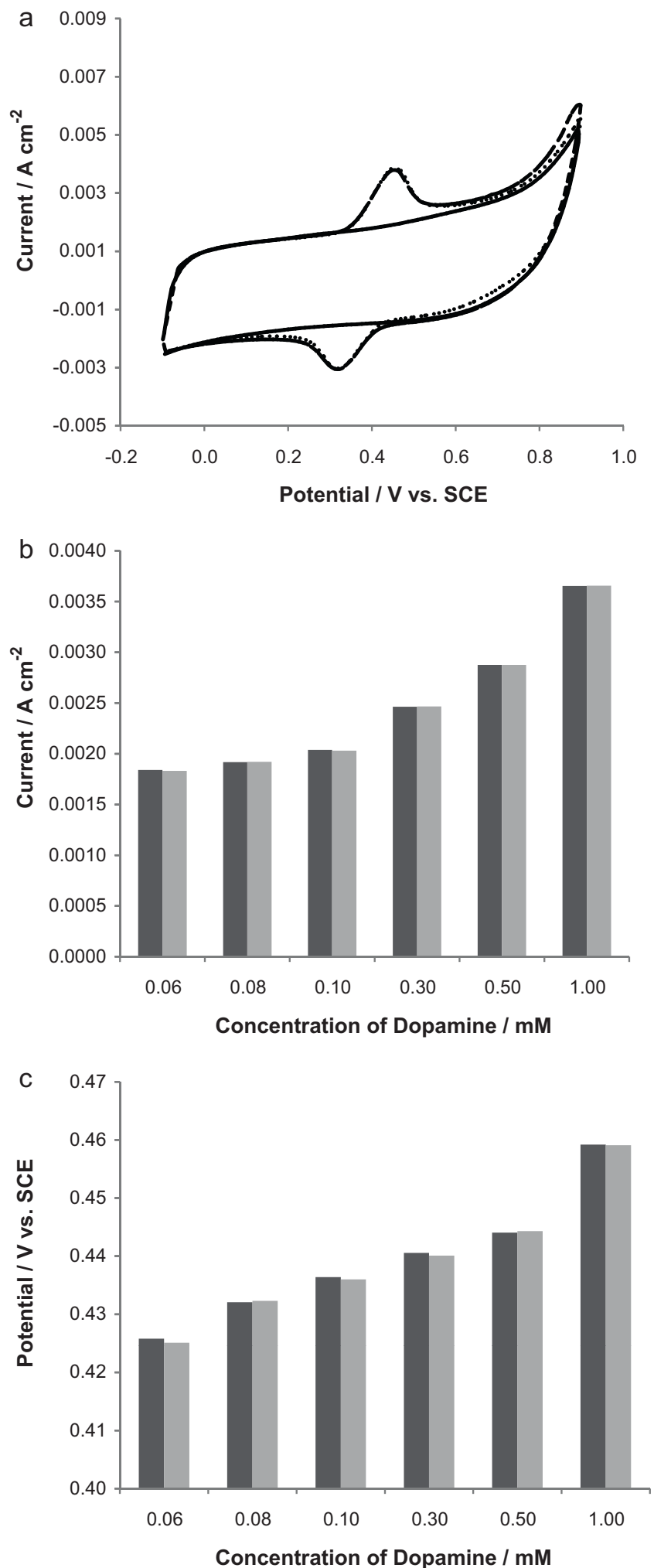

Fig. 3. (a) Cyclic voltammograms of a polypyrrole sulfonated $\beta$-cyclodextrin modified electrode in (- -) a $1.0 \times 10^{-3} \mathrm{M}$ dopamine/0.10 $\mathrm{M} \mathrm{Na} \mathrm{SO}_{4}$ solution, (-) a $1.0 \times 10^{-3} \mathrm{M}$ ascorbic acid/0.10 $\mathrm{M} \mathrm{Na}_{2} \mathrm{SO}_{4}$ solution and $(\cdots)$ a $1.0 \times 10^{-3} \mathrm{M}$ ascorbic acid $/ 1.0 \times 10^{-3} \mathrm{M}$ dopamine $/ 0.10 \mathrm{M} \mathrm{Na}_{2} \mathrm{SO}_{4}$ solution. Scan rate $=100 \mathrm{mV} \mathrm{s}^{-1}$. (b) Peak currents and (c) potentials, from the cyclic voltammograms, of dopamine as a function of the concentration of dopamine in the $(\square)$ presence $(n=3)$ and ( $\mathbf{E})$ absence $(n=4)$ of $1.0 \times 10^{-3} \mathrm{M}$ ascorbic acid in a $0.10 \mathrm{M} \mathrm{Na}_{2} \mathrm{SO}_{4}$ supporting electrolyte. The concentration ratio of ascorbic acid to dopamine in the combined solution was varied from $1.0\left(1.0 \times 10^{-3} \mathrm{M}\right.$ ascorbic acid and $1.0 \times 10^{-3} \mathrm{M}$ dopamine $)$ to $16.7\left(1.0 \times 10^{-3} \mathrm{M}\right.$ ascorbic acid and $6.0 \times 10^{-5} \mathrm{M}$ dopamine $)$. 
<smiles>NCCc1ccc(O)c(O)c1</smiles>

\section{$\stackrel{-2 \mathrm{H}^{+}}{\underset{-2 \mathrm{e}^{-}}{\rightleftharpoons}}$}<smiles>[NH3+]CCC1=CC(=O)C(=O)C=C1</smiles><smiles>O=C1O[C@@H]([C@H](O)CO)C(=O)C1=O</smiles>
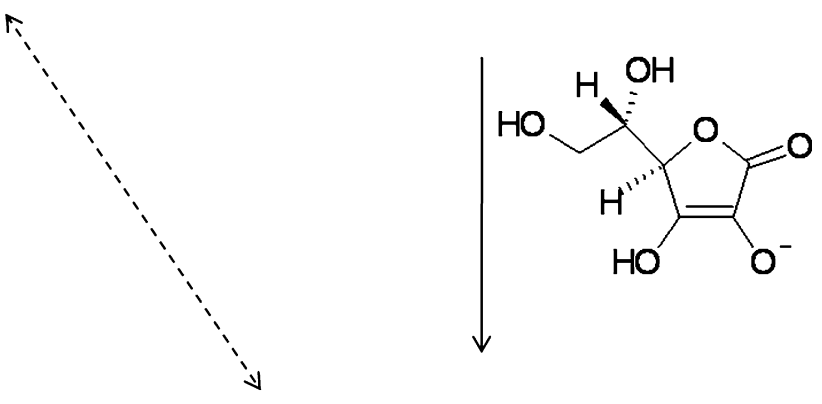

Scheme 1. Mechanism of the electrocatalytic oxidation of ascorbic acid by dopamine.

$(n=3)$. The fact that this high concentration of ascorbic acid does not interfere is remarkable given that it is significantly higher than the typical concentrations of ascorbic acid found in most biological samples.

These results show clearly that both $1.0 \times 10^{-3} \mathrm{M}$ and $1.0 \times 10^{-2} \mathrm{M}$ ascorbate do not interfere with the detection of dopamine, with the polypyrrole sulfonated $\beta$-cyclodextrin films eliminating the signal of ascorbic acid. This is somewhat rare given that the majority of reports for modified electrodes in the literature are related to the simultaneous determination of dopamine and ascorbic acid [39].

\subsection{Mechanism of sensing}

The data presented in Section 3.3 clearly show that the cyclodextrin-doped polypyrrole films have excellent selectivity. The sulfonated $\beta$-cyclodextrin is highly charged, with 7 to $11-\mathrm{SO}_{3}{ }^{-}$ groups. An important consideration is the number of sulfonated groups on each cyclodextrin that takes part in the doping process. If all the sulfonated groups on the $\beta$-cyclodextrin were involved in charge balance there would be considerable steric strain in the polymer matrix. Therefore, it is highly probable that some free sulfonated groups are present within the polymer. Furthermore, Naoi and co-workers [40], in studying the doping of polypyrrole with mono-, di- and tri-sulfonated naphthalene, concluded that the polypyrrole-trisulfonate doped films possessed free sulfonated groups without any charge compensation. This is consistent with the lack of any signal from the oxidation of the ascorbate anion, as the anion will be repelled from the negatively charged surface. On the other hand, the protonated dopamine $\left(\mathrm{p} K_{\mathrm{a}}=8.87\right)$ will be attracted to the interface. In addition, this local negative charge is sufficient to maintain the ascorbate $\left(\mathrm{p} K_{\mathrm{a}}=4.10\right)$ at a sufficient distance from the interface, enabling the reduction of the dopamine-o-quinone back to dopamine during the reduction cycle of the voltammogram, avoiding any, or little, regeneration of the dopamine through the ascorbate catalysed reaction.

In order to see if there was any binding interaction between the dopamine and the polypyrrole sulfonated $\beta$-cyclodextrin film, the Michaelis-Menten equation, $V=V_{\max }[S] / K_{\mathrm{m}}+[S]$, was applied to the constant potential amperometry data (Fig. 2(a)). The Michaelis-Menten equation describes the relationship between the rate of substrate conversion by an enzyme and the concentration of the substrate, where, $V$ is the rate of substrate conversion, $V_{\max }$ is the maximum rate of substrate conversion, [S] is the substrate concentration and $K_{\mathrm{m}}$ is the Michaelis constant. Even though the polypyrrole sulfonated $\beta$-cyclodextrin film is not an enzyme, the Michaelis-Menten equation can be applied to this system to gauge if there is any binding interaction between it and the dopamine. This is because cyclodextrins can mimic enzymecatalysed reactions and this has been well documented in the literature [41]. For this case, $V$ is equal to the current $I$, and subsequently $V_{\max }$ is equal to $I_{\max }$. The curve in Fig. 2(a) obeys the Michaelis-Menten equation with a correlation coefficient of 0.999 . The $K_{\mathrm{m}}$ and $I_{\max }$ were determined from this curve with values of $1.53 \times 10^{-3} \mathrm{M}$ and $1.17 \times 10^{-3} \mathrm{~A} \mathrm{~cm}^{-2}$ obtained, respectively. As this value of $K_{\mathrm{m}}$ is relatively high this would suggest that the dopamine [DA] interacts weakly with the polypyrrole sulfonated $\beta$-cyclodextrin film [PPy-SCD] to give the complex [PPy-SCD-DA], which can easily dissociate into the polypyrrole sulfonated $\beta$ cyclodextrin film [PPy-SCD] and the oxidised dopamine product, dopamine-o-quinone [DA-O-Q]. This can be summarised by

$[\mathrm{PPy}-\mathrm{SCD}]+[\mathrm{DA}] \underset{k_{-1}}{\stackrel{k_{1}}{\rightleftharpoons}}[\mathrm{PPy}-\mathrm{SCD}-\mathrm{DA}] \stackrel{k_{2}}{\longrightarrow}[\mathrm{PPy}-\mathrm{SCD}]+[\mathrm{DA}-\mathrm{O}-\mathrm{Q}]$

where $k_{1}$ and $k_{-1}$ are rate constants for the association and dissociation of dopamine and polypyrrole sulfonated $\beta$-cyclodextrin, respectively. The rate constant for the dissociation of converted dopamine (dopamine-o-quinone) is $k_{2}$.

The results acquired from the Michaelis-Menten kinetics indicate that there is an interaction between the dopamine and the polypyrrole sulfonated $\beta$-cyclodextrin film. The interaction could be purely electrostatic, with the negatively charged sulfonated groups on the cyclodextrin attracting the cationic dopamine to give an ion pair. Alternatively, it could be a combination of both an electrostatic interaction and the dopamine forming an inclusion complex with the sulfonated $\beta$-cyclodextrin.

Cyclic voltammetry was used to investigate the nature of this binding interaction between the dopamine and the sulfonated $\beta$-cyclodextrin in solution. These data were recorded with a fixed concentration of dopamine, $5.0 \times 10^{-4} \mathrm{M}$, at a glassy carbon electrode in a buffered citrate-phosphate, $\mathrm{pH}$ 6.0, solution. The concentration of the sulfonated cyclodextrin was varied from 

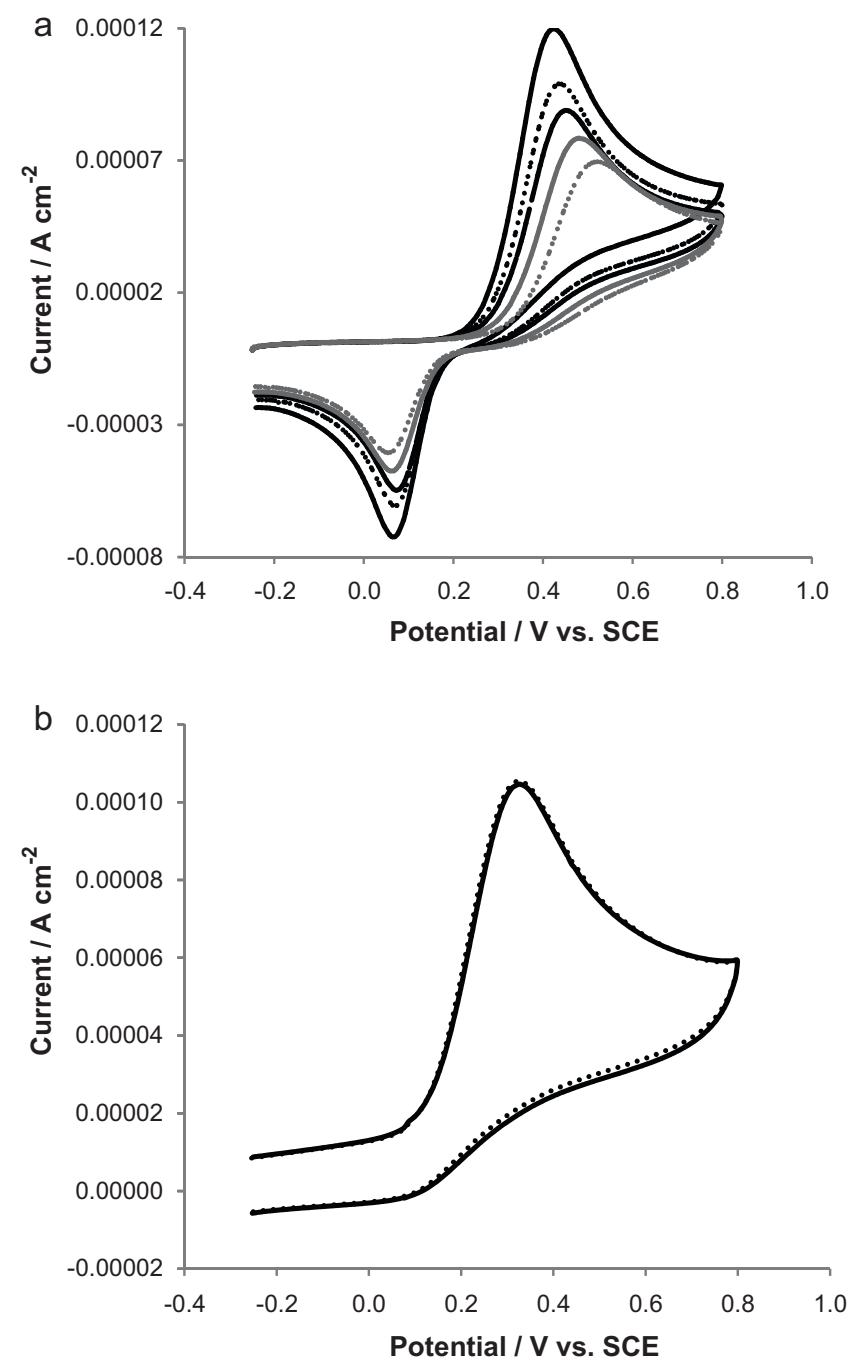

Fig. 4. (a) Cyclic voltammograms of a bare glassy carbon electrode in (-) $5.0 \times 10^{-4} \mathrm{M}$ dopamine and in $5.0 \times 10^{-4} \mathrm{M}$ dopamine $/\left(\ldots\right.$ ) $2.0 \times 10^{-2} \mathrm{M}$, ( ) $1.0 \times 10^{-2} \mathrm{M}$, (- -) $5.0 \times 10^{-3} \mathrm{M}$ and in ( $\left.\cdots\right) 2.5 \times 10^{-3} \mathrm{M}$ sulfonated $\beta$-cyclodextrin. All solutions were made up in a $0.30 \mathrm{M}$ citrate phosphate buffer solution ( $\mathrm{pH}$ of all solutions $\sim 6.0$ ). Scan rate $=50 \mathrm{mV} \mathrm{s}^{-1}$. Electrochemical window: $-0.25 \mathrm{~V}$ to $0.80 \mathrm{~V}$ vs. SCE. (b) Cyclic voltammograms of a bare glassy carbon electrode in (-) $5.0 \times 10^{-4} \mathrm{M}$ ascorbic acid and in ( $\left.\cdots\right) 5.0 \times 10^{-4} \mathrm{M}$ ascorbic acid $/ 1.0 \times 10^{-2} \mathrm{M}$ sulfonated $\beta$-cyclodextrin. All solutions were made up in a $0.30 \mathrm{M}$ citrate phosphate buffer solution ( $\mathrm{pH}$ of all solutions $\sim 6.0$ ). Scan rate $=50 \mathrm{mV} \mathrm{s}^{-1}$. Electrochemical window: $-0.25 \mathrm{~V}$ to $0.80 \mathrm{~V}$ vs. SCE.

$2.0 \times 10^{-2} \mathrm{M}$ to $2.5 \times 10^{-3} \mathrm{M}$ to give dopamine-containing solutions with an excess of the anionic sulfonated $\beta$-cyclodextrin, while the $0.3 \mathrm{M}$ buffer solution provided a near constant ionic strength. The voltammograms recorded for the pure dopamine solution are compared to the data recorded in the presence of the sulfonated $\beta$ cyclodextrin in Fig. 4(a). On addition of sulfonated $\beta$-cyclodextrin to the dopamine solution, there is a clear anodic shift in the peak oxidation potential and a decrease in the peak oxidation current. In contrast, no evidence of any interaction was observed between the ascorbate anion and the sulfonated $\beta$-cyclodextrin when a similar analysis was carried out (Fig. 4(b)). This reduction in the peak current and the anodic shift of the peak potentials for the oxidation of the analyte are consistent with the formation of an inclusion complex $[42,43]$. The increase in the oxidation potential is connected to the fact that it is more difficult to oxidise the included dopamine, while the decrease in the peak currents is consistent with a lower diffusion coefficient of the included dopamine compared to that of free dopamine. The sulfonated $\beta$-cyclodextrin is large and bulky and this will give rise to a measurable decrease in the diffusion coefficient of the encapsulated dopamine. Although these data are consistent with the formation of an inclusion complex the driving force for this inclusion event may be the electrostatic attraction between the anionic sulfonated $\beta$-cyclodextrin and the cationic dopamine. Indeed our studies show that there is no apparent interaction between the neutral $\beta$-cyclodextrin and dopamine in solution.

Interestingly, there is no change in the potential at which the dopamine-o-quinone is reduced and converted back to dopamine, Fig. 4(a). For example, the peak potential is $0.064 \mathrm{~V}$ vs. SCE in the absence of the sulfonated $\beta$-cyclodextrin and $0.060 \mathrm{~V}$ vs. SCE in the presence of the $2.0 \times 10^{-2} \mathrm{M}$ sulfonated $\beta$-cyclodextrin. These observations illustrate that once the included dopamine is converted to dopamine-o-quinone, it is expelled from the cavity, enabling the detection of dopamine in subsequent cycles, corroborating the Michaelis-Menten analysis.

Assuming that the cavity is accessible when the cyclodextrin is doped within the polypyrrole matrix, then an inclusion complex between the dopamine and the cavity is likely. Interestingly, Bidan et al. [26] showed that N-methylphenothiazine (NMP) was encapsulated within the cyclodextrin cavity by simply immersing the polypyrrole-sulfonated $\beta$-cyclodextrin film in an acetonitrile $\left(\mathrm{CH}_{3} \mathrm{CN}\right)$ solution containing NMP, indicating that the cavities are available for suitable guest molecules.

\section{Conclusions}

A sulfonated $\beta$-cyclodextrin doped polypyrrole film was formed at $0.80 \mathrm{~V}$ vs. SCE in a $0.20 \mathrm{M}$ pyrrole and $0.01 \mathrm{M}$ sulfonated $\beta$ cyclodextrin solution. This polymer has excellent selectivity for the detection of dopamine in the presence of ascorbate. The ascorbate anion is not detected. A linear calibration curve was obtained to give a sensitivity of $0.886 \mu \mathrm{A} \mu \mathrm{M}^{-1}$ and a detection limit of $3.2 \times 10^{-6} \mathrm{M}$ for dopamine.

\section{Acknowledgments}

The authors appreciate the financial support from the Irish Research Council for Science, Engineering and Technology (IRCSET) and the Tyndall National Institute for the Tencor analysis which was carried out under the National Access Programme funded by Science Foundation Ireland.

\section{References}

[1] P. Revest, A. Longstaff, Molecular Neuroscience, Taylor \& Francis, 1998.

[2] R.F. Thompson, The Brain: A Neuroscience Primer, W.H. Freeman and Company (1993).

[3] R.D. O'Neill, Long-term monitoring of brain dopamine metabolism in vivo with carbon paste electrodes, Sensors 5 (2005) 317-342.

[4] P.E.M. Phillips, G.D. Stuber, M. Heien, R.M. Wightman, R.M. Carelli, Subsecond dopamine release promotes cocaine seeking, Nature 422 (2003) 614-618.

[5] G.S. Wilson, M.A. Johnson, In-vivo electrochemistry: what can we learn about living systems? Chem. Rev. 108 (2008) 2462-2481.

[6] J.P. Lowry, R.D. O’Neill, Encyclopedia of Sensors, Neuroanalytical Chemistry In Vivo Using Electrochemical Sensors, American Scientific Publishers, 2006.

[7] U.E. Majewska, K. Chmurski, K. Biesiada, A.R. Olszyna, R. Bilewicz, Dopamine oxidation at per(6-deoxy-6-thio)-alpha-cyclodextrin monolayer modified gold electrodes, Electroanalysis 18 (2006) 1463-1470.

[8] L. Zhang, X. Jiang, Attachment of gold nanoparticles to glassy carbon electrode and its application for the voltammetric resolution of ascorbic acid and dopamine, J. Electroanal. Chem. 583 (2005) 292-299.

[9] S. Alwarappan, G.D. Liu, C.Z. Li, Simultaneous detection of dopamine, ascorbic acid, and uric acid at electrochemically pretreated carbon nanotube biosensors, Nanomed. Nanotechnol. Biol. Med. 6 (2010) 52-57.

[10] S.M. Chen, W.Y. Chzo, Simultaneous voltammetric detection of dopamine and ascorbic acid using didodecyldimethylammonium bromide (DDAB) filmmodified electrodes, J. Electroanal. Chem. 587 (2006) 226-234.

[11] G. Hu, Y. Liu, J. Zhao, S. Cui, Z. Yang, Y. Zhang, Selective response of dopamine in the presence of ascorbic acid on L-cysteine self-assembled gold electrode, Bioelectrochemistry 69 (2006) 254-257. 
[12] L. Lin, J. Chen, H. Yao, Y. Chen, Y. Zheng, X. Lin, Simultaneous determination of dopamine, ascorbic acid and uric acid at poly(Evans Blue) modified glassy carbon electrode, Bioelectrochemistry 73 (2008) 11-17.

[13] S. Thiagarajan, S.-M. Chen, Preparation and characterization of PtAu hybrid film modified electrodes and their use in simultaneous determination of dopamine, ascorbic acid and uric acid, Talanta 74 (2007) 212-222.

[14] G. Erdogdu, H.B. Mark, A.E. Karagozler, Voltammetric resolution of ascorbic acid and dopamine at conducting polymer electrodes, Anal. Lett. 29(1996)221-231.

[15] S. Hou, N. Zheng, H. Feng, X. Li, Z. Yuan, Determination of dopamine in the presence of ascorbic acid using poly(3,5-dihydroxy benzoic acid) film modified electrode, Anal. Biochem. 381 (2008) 179-184.

[16] R. Zhang, G.-D. Jin, D. Chen, X.-Y. Hu, Simultaneous electrochemical determination of dopamine, ascorbic acid and uric acid using poly(acid chrome blue $\mathrm{K}$ ) modified glassy carbon electrode, Sens. Actuators B 138 (2009) 174-181.

[17] Y. Zhang, G. Jin, Y. Wang, Z. Yang, Determination of dopamine in the presence of ascorbic acid using poly (Acridine red) modified glassy carbon electrode, Sensors 3 (2003) 443-450.

[18] H. Zhao, Y. Zhang, Z. Yuan, Study on the electrochemical behaviour of dopamine with poly(sulfosalicylic acid) modified glassy carbon electrode, Anal. Chim. Acta 441 (2001) 117-122.

[19] Y. Li, P. Wang, L. Wang, X. Lin, Overoxidized polypyrrole film directed singlewalled carbon nanotubes immobilization on glassy carbon electrode and its sensing applications, Biosens. Bioelectron. 22 (2007) 3120-3125.

[20] D. Zheng, J. Ye, L. Zhou, Y. Zhang, C. Yu, Simultaneous determination of dopamine, ascorbic acid and uric acid on ordered mesoporous carbon/Nafion composite film, J. Electroanal. Chem. 625 (2009) 82-87.

[21] J. Szejtli, Past, present, and future of cyclodextrin research, Pure Appl. Chem. 76 (2004) 1825-1845.

[22] N. Izaoumen, D. Bouchta, H. Zejli, M.E. Kaoutit, K.R. Temsamani, The electrochemical behaviour of neurotransmitters at a poly(pyrrole-b-cyclodextrin) modified glassy carbon electrode, Anal. Lett. 38 (2005) 1869-1885.

[23] D. Bouchta, N. Izaoumen, H. Zejli, M.E. Kaoutit, K.R. Temsamani, A novel electrochemical synthesis of poly-3-methylthiophene- $\gamma$-cyclodextrin film. Application for the analysis of chlorpromazine and some neurotransmitters, Biosens. Bioelectron. 20 (2005) 2228-2235.

[24] G. Alarcon-Angeles, B. Perez-Lopez, M. Palomar-Pardave, M.T. Ramirez-Silva, S. Alegret, A. Merkoci, Enhanced host-guest electrochemical recognition of dopamine using cyclodextrin in the presence of carbon nanotubes, Carbon 46 (2008) 898-906.

[25] K.R. Temsamani, H.B. Mark Jr., W. Kutner, A.M. Stalcup, A simple one-step electrosynthesis of poly (pyrrole-sulfated B-cyclodextrin films, J. Solid State Electrochem. 6 (2002) 391-395.

[26] G. Bidan, C. Lopez, F. Mendes-Viegas, E. Vieil, A. Gadelle, Incorporation of sulphonated cyclodextrins into polypyrrole: an approach for the electrocontrolled delivering of neutral drugs, Biosensi Bioelectroni 10 (1995) 219-229.

27] D.A. Reece, S.F. Ralph, G.G. Wallace, Metal transport studies on inherently conducting polymer membranes containing cyclodextrin dopants, J. Membr. Sci. 249 (2005) 9-20.

[28] S. Shahrokhian, S. Bozorgzadeh, Electrochemical oxidation of dopamine in the presence of sulfhydryl compounds: application to the square-wave voltammetric detection of penicillamine and cysteine, Electrochim. Acta 51 (2006) 4271-4276.

[29] S.M. Chen, J.Y. Chen, R. Thangamuthu, Electrochemical preparation of poly(Malachite green) film modified nafion-coated glassy carbon electrode and its electrocatalytic behavior towards NADH, dopamine and ascorbic acid, Electroanalysis 19 (2007) 1531-1538.

[30] H.X. Ju, J.G. Ni, Y. Gong, H.Y. Chen, D. Leech, Electrocatalytical oxidation and determination of dopamine at redox polymer/nafion modified electrodes, Anal. Lett. 32 (1999) 2951-2964.

[31] A.F. Diaz, J.I. Castillo, J.A. Logan, W.Y. Lee, Electrochemistry of conducting polypyrrole films, J. Electroanal. Chem. 129 (1981) 115-132.

[32] J.M. Fonner, L. Forciniti, H. Nguyen, J.D. Byrne, Y.F. Kou, J. Syeda-Nawaz, C.E. Schmidt, Biocompatibility implications of polypyrrole synthesis techniques, Biomed. Mater. 3 (2008)
[33] M.C. Henstridge, E.J.F. Dickinson, M. Aslanoglu, C. Batchelor-McAuley, R.G. Compton, Voltammetric selectivity conferred by the modification of electrodes using conductive porous layers or films: the oxidation of dopamine on glassy carbon electrodes modified with multiwalled carbon nanotubes, Sens. Actuators B 145 (2010) 417-427.

[34] G.P. Keeley, M.E.G. Lyons, The effects of thin layer diffusion at glassy carbon electrodes modified with porous films of single-walled carbon nanotubes, Int. J. Electrochem. Sci. 4 (2009) 794-809.

[35] P. Zhang, F.-H. Wu, G.-C. Zhao, X.-W. Wei, Selective response of dopamine in the presence of ascorbic acid at multi-walled carbon nanotube modified gold electrode, Bioelectrochemistry 67 (2005) 109-114.

[36] A.I. Gopalan, K.-P. Lee, K.M. Manesh, P. Santhosh, J.H. Kim, J.S. Kang, Electrochemical determination of dopamine and ascorbic acid at a novel Au nanoparticles distribute poly(4-aminothiophenol) modified electrode, Talanta 71 (2007) 1774-1781.

[37] A. Balamurugan, S.-M. Chen, Poly(3,4-ethylenedioxythiophene-co-(5-amino2-naphthalenesulfonic acid)) (PEDOT-PANS) film modified glassy carbon electrode for selective detection of dopamine in the presence of ascorbic acid and uric acid, Anal. Chim. Acta 596 (2007) 92-98

[38] M. Ferreira, L.R. Dinelli, K. Wohnrath, A.A. Batista, O.N. Oliveira, Langmuir-Blodgett films from polyaniline/ruthenium complexes as modified electrodes for detection of dopamine, Thin Solid Films 446 (2004) 301306.

[39] N.F. Atta, M.F. El-Kady, Novel poly(3-methylthiophene)/Pd, Pt nanoparticle sensor: synthesis, characterization and its application to the simultaneous analysis of dopamine and ascorbic acid in biological fluids, Sens. Actuators B 145 (2010) 299-310.

40] S. Suematsu, Y. Oura, H. Tsujimoto, H. Kanno, K. Naoi, Conducting polymer films of cross-linked structure and their QCM analysis, Electrochim. Acta 45 (2000) 3813-3821.

[41] R. Kataky, E. Morgan, Potential of enzyme mimics in biomimetic sensors: a modified-cyclodextrin as a dehydrogenase enzyme mimic, Biosens. Bioelectron. 18 (2003) 1407-1417.

[42] E. Coutouli-Argyropoulou, A. Kelaidopoulou, C. Sideris, G. Kokkinidis, Elec trochemical studies of ferrocene derivatives and their complexation by [beta]-cyclodextrin, J. Electroanal. Chem. 477 (1999) 130-139.

[43] X.-J. Dang, M.-Y. Nie, T. Jian, H.-L. Li, Inclusion of the parent molecules of some drugs with [beta]-cyclodextrin studied by electrochemical and spectrometric methods, J. Electroanal. Chem. 448 (1998) 61-67.

\section{Biographies}

Claire C. Harley completed a double honours degree in Chemistry and Mathematics in 2005 and a Ph.D. in Chemistry in 2009 at the National University of Ireland Maynooth where she is currently a postdoctoral researcher. Her main research interests are in polymers and electrochemical sensors.

Denise Rooney was awarded her Ph.D. in Chemistry in 1991 from Queen's Univer sity Belfast. Her thesis was on 'Time-resolved Raman spectroscopy and photolysis of transition metal carbene complexes'. She began working in the Department of Chemistry at the National University of Ireland Maynooth in 1994 and she is currently a senior lecturer, researching in the field of inorganic chemistry. Her research interests lie in the area of organometallic chemistry, polymer synthesis and the development of redox active materials.

Carmel B. Breslin completed her university education at the National University of Ireland, Galway, graduating in 1987 with a degree in chemistry and again in 1990 with a Ph.D. in electrochemistry. She then joined the National University of Ireland, Maynooth where she is now professor of physical chemistry. Her research publications and interests are in electrochemistry and materials. 